\title{
Experimental Verification of MPPT Algorithms for Photovoltaic systems
}

\author{
Sachin Angadi, Divya C. Badiger, Udaykumar R. Yaragatti, A. B. Raju
}

\begin{abstract}
Changing meteorological conditions influence the output power of the Photovolataic systems, which affect the overall performance of the system, in turn reduces the overall efficiency. So, to draw maximal power from the PV system a technique called maximum power point tracking (MPPT) is incorporated. Two perturbations-based algorithms are presented in this paper are Perturb and Observe $(P \& O)$, and Modified drift-free perturb and observe $(M P \& O)$. Fixed step size duty ratio is used in both of these algorithms. The boost converter is used between the photovoltaic module and the resistive Load. The simulation and experimental results for $250 \mathrm{~W} P V$ module are presented. The simulation studies are carried out in MATLAB SIMULINK. The algorithms are implemented using TMS320F28069M.
\end{abstract}

Keywords: Boost converter, Duty ratio, Maximum Power Point Tracking, Perturb and Observe, Modified drift-free Perturb and Observe.

\section{INTRODUCTION}

Due to the depletion of non-renewable energy sources, it is necessary to make efficient employment of available renewable energy sources [1]. They are used to cater to an increase in electrical energy demand. Among all the available forms of energy, solar energy is more abundant in nature, which is clean and eco-friendly [3]. The PV domain is the most efficient way of generating electricity [15], as it requires low operating costs. There is one unique point in the power versus voltage graph, where generated energy is maximum called maximum power point [6]. Maximum power point trackers are being used to make our system to operate at MPP [4].

Generally, the system will not function at MPP, where we can extract maximal power. [7] The Boost converter is adopted as an interface amid the photovoltaic module and the resistive load. It matches the load impedance to the source impedance by varying the duty ratio appropriately, so that energy transferred is maximum to the load.

Algorithms presented in this paper make use of direct duty ratio control under varying weather conditions because basic electrical quantities (Voltage, Current) of PV is given as inputs to the controller. There are many methods proposed for MPP Tracking [14].

Revised Manuscript Received on March 5, 2020.

Sachin Angadi, Assistant Professor, Department of Electrical \& Electronics Engineering, KLE Technological University, Hubballi.

Divya Chandrashekhar Badiger, Department of Electrical and Electronics Engineering, KLE Technological University, Hubballi, India.

Udaykumar R. Yaragatti, Lecturer, Department of Electrical and Electronics Engineering, NITK Surathkal, India,

Sri A. B. Raju, Professor and Head, Department of Electrical and Electronics Engineering, B. V. B. College of Engineering and Technology Campus, K. L. E. Technological University, Hubballi.

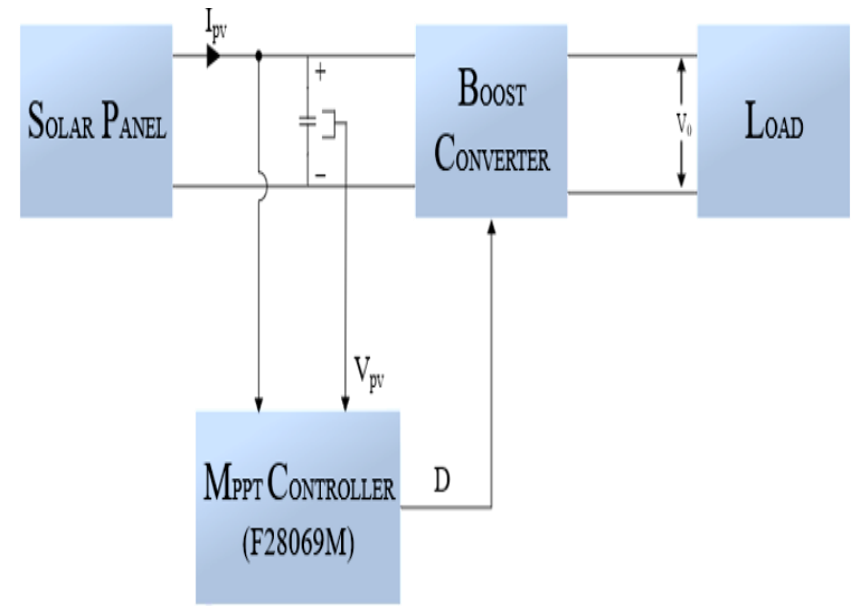

Fig. 1.Photovolatic System Block Diagram

The widely implemented algorithm is Perturb and Observe, which is the simplest and performs quick convergence. $\mathrm{P} \& \mathrm{O}$ algorithm involves perturbation in operating voltage [9]. There are numerous maximum power tracking methods. Constant voltage method, Fractional short circuit current, Fractional Short circuit voltage, P\&O, and MP\&O. The Constant voltage method is the most simple and low-cost MPPT controller [16]. It only takes PV Voltage as input, but the efficiency is very poor under varying environmental conditions, constant voltage method can be implemented in regions where there are no abrupt changes in ecological terms.

Fractional short circuit current is a fast and straightforward way of finding the MPP. But it does not track the exact MPP more accurately. The drawback of using this Algorithm is that there will be a periodic loss in power while measuring the short circuit current. Fractional Open Circuit Voltage method is similar to that of Fractional open circuit current method. It also does not track the exact MPP. There will be a power loss while measuring the open-circuit voltage.

The drawback of this Algorithm is, it does not make an accurate decision under varying weather conditions [11]. The operating point is made to vacillate, around the peak point. The modified drift-free P\&O Algorithm with experimental proof is presented to address the weaknesses of the $\mathrm{P} \& \mathrm{O}$ algorithm [5], [10], [12]. Modeling and simulation are carried, on MATLAB SIMULINK.

In section III, the modeling of photovoltaic, $\mathrm{P} \& \mathrm{O}$, and MP\&O is explained with relevant mathematical equations. The experimental setup is described in section IV. In section $\mathrm{V}$, implementations of the MPPT algorithm are discussed to choose the best algorithm for MPPT tracking. The conclusion is given in the conclusion section VI.

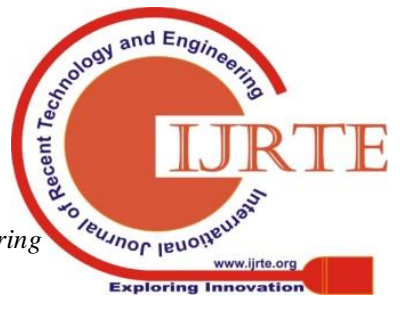




\section{SYSTEM SPECIFICATIONS}

The PV system block diagram is illustrated in Fig.1. It comprises of PV module, boost converter, MPPT controller, and the resistive load. The module generates electrical energy by the application of solar light on its surface. The electrical quantities such as voltage and current from the PV module are

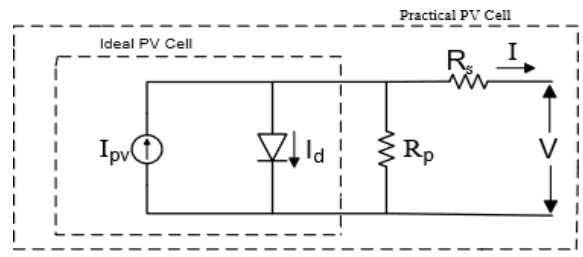

Fig. 2. PV cell

Equivalent circuit

given as inputs to the MPPT controller. The controller decides the duty ratio, to where the maximum amount of power can be generated. The duty ratio is given as an input to the dc-dc converter.

\section{MATHEMATICAL MODELING}

\section{A. Mathematical Modeling of PV Cell}

A Fig. 2 represent the ideal and practical PV cell. The solar PV system is composed of photovoltaic cells. Cells are arranged to form panels, and panels are grouped to constitute an array [8]. The mathematical equations are defined below. The PV cell equation is given in (1).

$I=I_{p h}-I_{0}\left(\exp \left(\frac{V+I \cdot R_{s}}{V_{T}}\right)-1\right)-\left(\frac{V+I \cdot R_{s}}{R_{P}}\right)$

$\mathrm{I}_{\mathrm{ph}}=$ Insolation current $[\mathrm{A}]$

$\mathrm{I}=$ Total current of the cell [A]

$\mathrm{I}_{\mathrm{o}}=$ Reverse saturation current $[\mathrm{A}]$

$\mathrm{V}=$ Total Voltage of the cell [V]

$\mathrm{R}_{\mathrm{s}}$ and $\mathrm{R}_{\mathrm{p}}=$ Resistances [ohms]

$\mathrm{V}_{\mathrm{T}}=$ Thermal Voltage $[\mathrm{V}]$

The Total Current I is given by (2)

$I=I p h-I_{D}-I_{R P}$

Where $I_{R P}$ is the current through resistance $R_{p}$. The diode current is given by,

$$
I_{D}=\left(\exp \left(\frac{V+I \cdot R_{s}}{V_{T} \cdot N_{s}}\right)-1\right) I
$$

Where $\mathrm{N}_{\mathrm{s}}=$ Total cells connected in series

Shunt resistance current is given by (4),

$$
I_{R P}=\left(\frac{V+I \cdot R_{S}}{R_{P}}\right)
$$

Insolation current is given by (5),

$$
I_{p h}=\left[\mu_{s c}\left(T_{c}-T_{r e f}+I_{s c}\right)\right] G_{p u}
$$

Where, $\mu_{s c}$ Coefficient of short circuit,

$T_{c}$ : Operating condition temperature,

$T_{\text {ref }}$ : Temperature of reference

The reverse saturation current is given by (6):

$$
I_{o}=I_{s c} / \exp \left(\frac{q \cdot V_{o c}}{\eta \cdot K \cdot T_{c} \cdot V_{T}}\right)
$$

$\mathrm{K}$ : Boltzmann's constant $\left(1.381 \times 10^{-23}\right)[\mathrm{J} / \mathrm{K}]$ $\mathrm{q}$ : Charge of an electron $\left(1.602 \times 10^{-19}\right)[\mathrm{C}]$

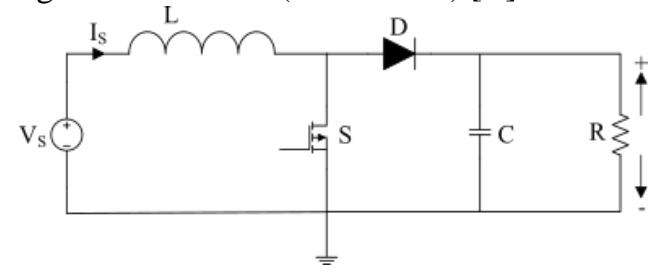

Fig. 3. Schematic of Boost Converter

\section{B. Boost Converter}

Fig. 3 gives the schematic of the PV fed boost converter. It boosts the voltage at the output terminal. For charging applications boost converters are being used. It is also called a step-up transformer. The boost converter is employed to transfer maximal amount power to the load [2].

The equation that connects input $\left(\mathrm{V}_{\mathrm{S}}\right)$, output voltage $\left(\mathrm{V}_{\mathrm{o}}\right)$, and the duty ratio is computed as:

$$
V o=\frac{V s}{(1-D)}
$$

Inductance minimum value is:

$$
L_{\min }=\frac{\left(1-D^{2}\right) D R}{2 f}
$$

where, $\mathrm{D}=$ Duty ratio

$\mathrm{R}=$ Resistance of Load $[\Omega]$

$\mathrm{f}=$ Switching frequency $[\mathrm{Hz}]$

Capacitance minimum value is given by (9),

$$
C=\frac{D}{R\left(\frac{\Delta V o}{V o}\right) f}
$$

The Relation between the Duty ratio, $\mathrm{R}_{\mathrm{mpp}}, \mathrm{R}_{\text {load }}$ is given by (10).

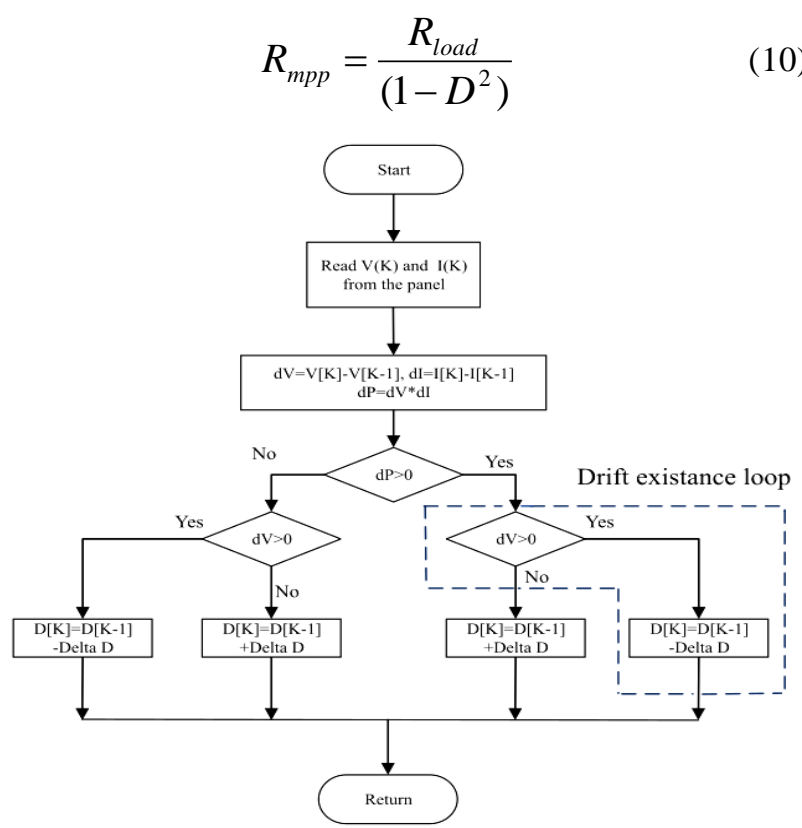

Fig. 4.P\&O Algorithm Flowchart 


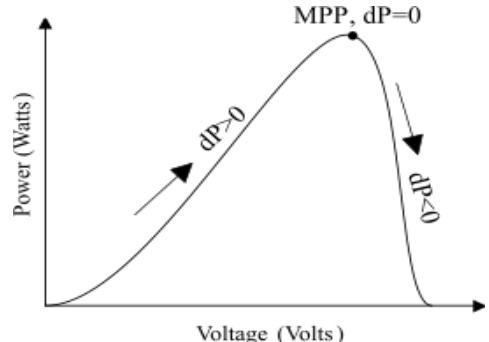

Fig. 5.P-V Characteristics of P\&O Algorithm

\section{Perturb and Observe}

$\mathrm{P} \& \mathrm{O}$ is the primary algorithm employed in the MPPT algorithm (Fig. 4). The power versus voltage characteristics is given in Fig.5. It perturbs the voltage under changing environmental conditions. The $\mathrm{dP}$ increases at the left side of maximum power point decreases at the right side of maximum power point and is zero at maximum power point. Power changes with changes in irradiance and temperature values, with changes in power, duty ratio, adjust itself accordingly. The duty ratio fluctuates around the MPP. The $\mathrm{dV}$ and $\mathrm{dP}$, are obtained by calculating the Variation between the voltage and power values at $\mathrm{K}^{\mathrm{th}}$ instant to that of the $(\mathrm{K}+1)^{\text {th }}$ instant. In this algorithm, it examines the power and voltage values at two different instants and makes the decision.

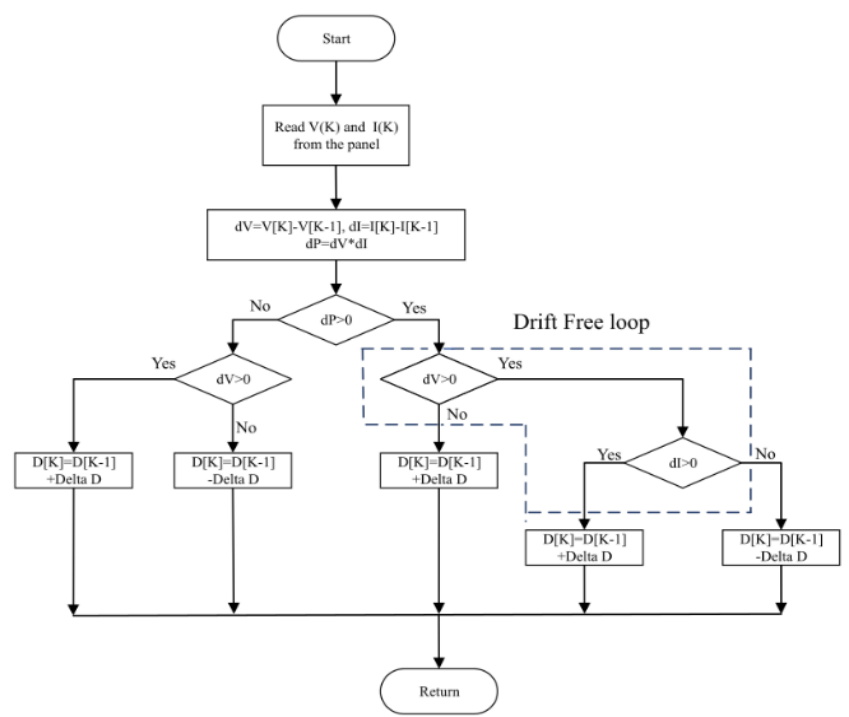

Fig. 6.Modified drift-free P\&O Algorithm Fowchart

\section{Modified drift-free P\&O}

The $\mathrm{P} \& \mathrm{O}$ algorithms shortcoming is its tracking ability under varying environmental conditions and poor dynamic performance when a level variation in irradiance value occurs.

Flowchart of modified $\mathrm{P} \& \mathrm{O}$ algorithm given in Fig.6. The algorithm overcomes the problem of drift by comparing the voltage and current values and accurately adjusting the duty ratio. The conventional algorithm compares voltage and power and takes the decision, but in this algorithm, if the voltage and power condition in the flowchart is true, it also examines the current to make a decision [13].

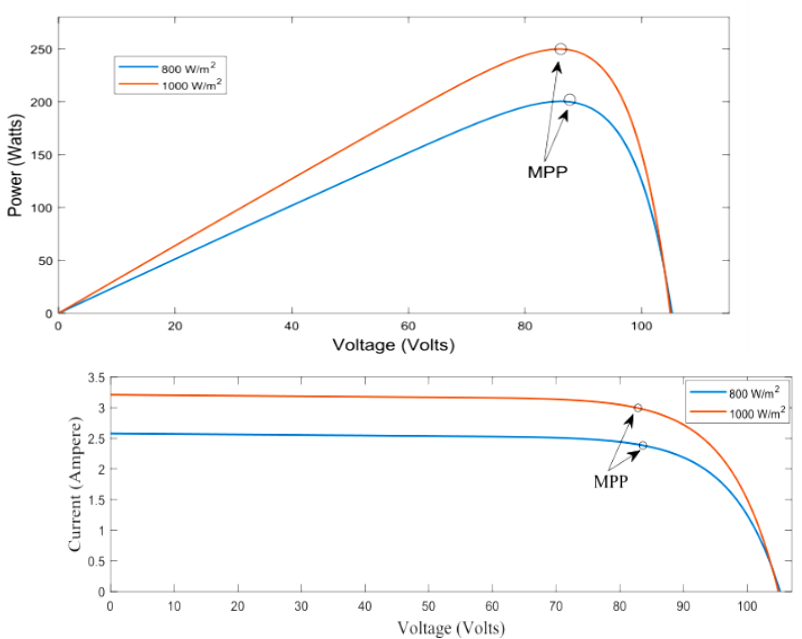

Fig. 7.Current versus Voltage curve

Fig. 8.Power versus Voltage curve

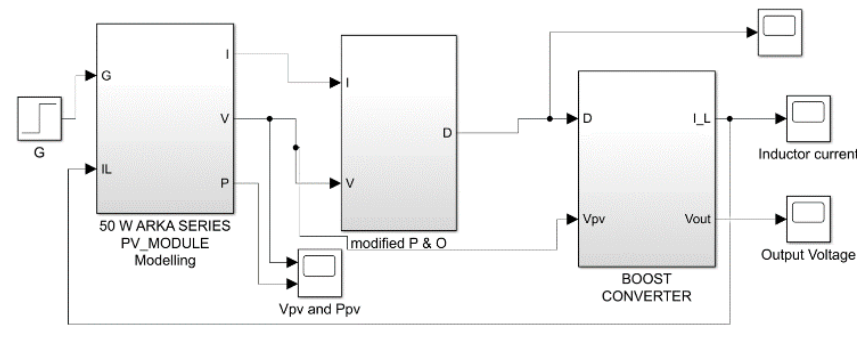

Fig. 9.Fig. 9.Simulink model of MPPT system Table- I: Solar PV module specifications

\begin{tabular}{|c|c|}
\hline Parameters & Values \\
\hline Maximum System Voltage & $1000 \mathrm{~V}$ \\
\hline Open Circuit Voltage $V_{o c}$ & $21.0 \mathrm{~V}$ \\
\hline Short Circuit Current $I_{s c}$ & $3.17 \mathrm{~A}$ \\
\hline Maximum Power $P_{\max }$ & $50.0 \mathrm{~W}$ \\
\hline Current at $P_{\max }\left(I_{\max }\right)$ & $2.94 \mathrm{~A}$ \\
\hline Voltage at $P_{\max }\left(V_{\operatorname{mpp}}\right)$ & $17.0 \mathrm{~V}$ \\
\hline Load Resistance $R_{\text {load }}$ & $250 \Omega$ \\
\hline
\end{tabular}

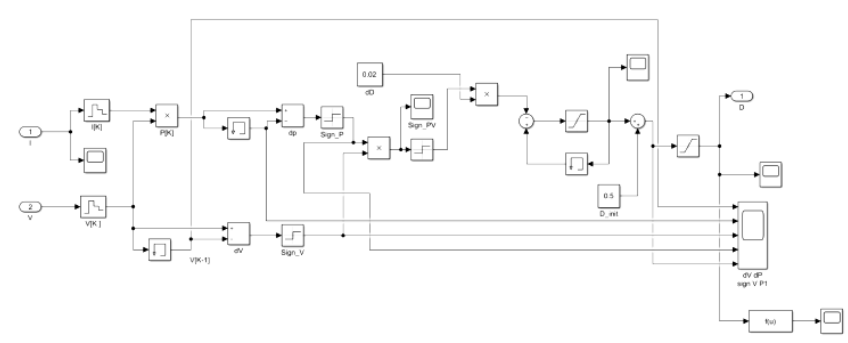

Fig. 10. Fig. 10. P\&O Algorithm SIMULINK model

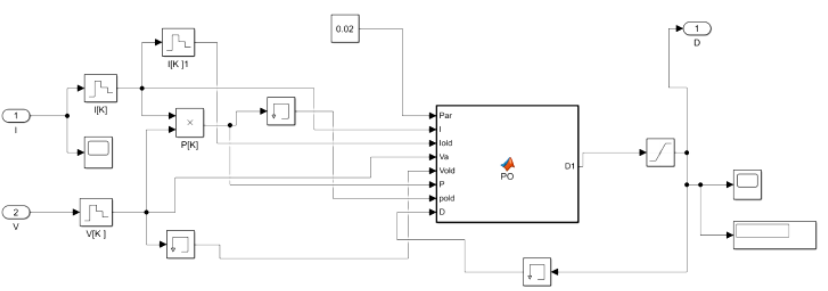

Fig. 11. Fig. 11. Modified P\&O SIMULINK model

\section{RESULTS AND DISCUSSIONS}

\section{A. Simulation studies}

Fig. $7 \& 8$ give the I-V and $\mathrm{P}-\mathrm{V} \quad$ characteristics respectively for $800 \mathrm{~W} / \mathrm{m}^{2}$ and 
$1000 \mathrm{~W} / \mathrm{m}^{2}$ irradiance values. The PV system Simulink model is given in Fig. 9. The data in Table- I indicates the PV module specifications. In this paper, the value of one inductor is $560 \mu \mathrm{H}$. Six such inductors are connected in series which will sum up to $3.36 \mathrm{mH}$. Input capacitance of $1250 \mu \mathrm{F}$ is chosen to extract $\mathrm{V}_{\mathrm{pv}}$ from the PV system. Output capacitance is $2350 \mu \mathrm{F}$. The Simulink model of both the presented algorithms is given by in Fig. $10 \& 11$ respectively.
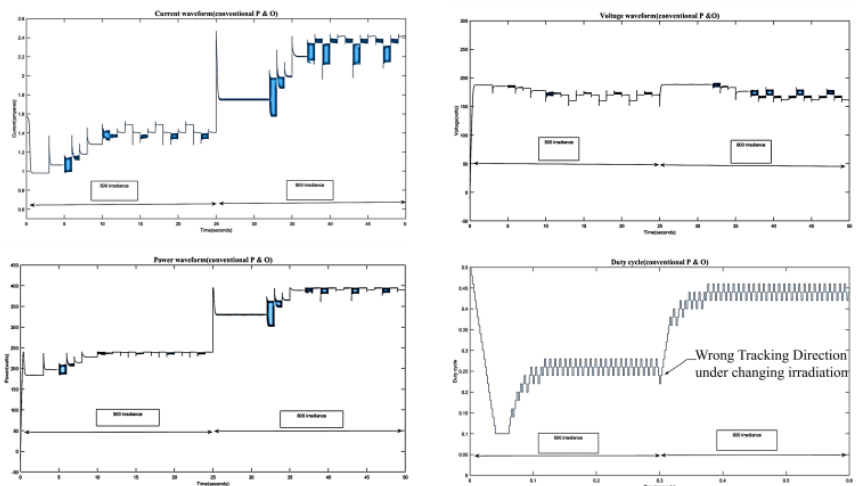

Fig. 12. Fig. 12: Current, voltage power and duty cycle waveforms for Conventional P\&O MPPT at irradiance values from $500 \mathrm{~W} / \mathrm{m} 2-800 \mathrm{~W} / \mathrm{m} 2$
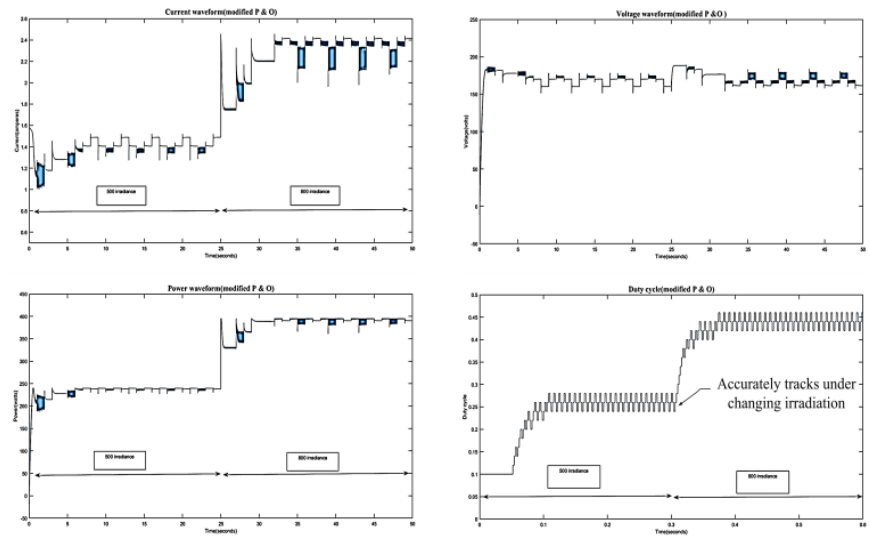

Fig. 13. Fig. 13: Current, voltage power and duty cycle waveforms for modified drift free P\&O MPPT at irradiance values from $500 \mathrm{~W} / \mathrm{m} 2-800 \mathrm{~W} / \mathrm{m} 2$

The simulation results of both algorithms are presented in Fig. 12 and Fig. 13 respectively.

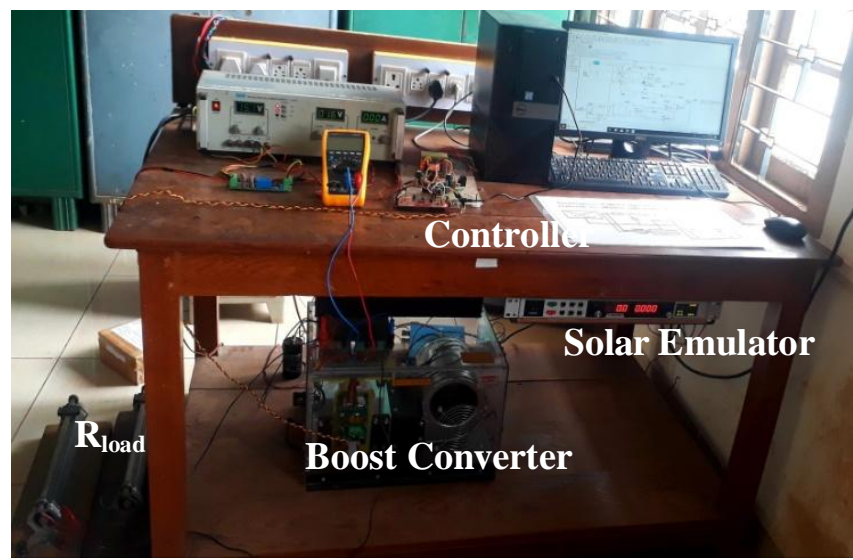

Fig. 14. Fig. 14. Hardware setup of MPPT system

Table- II: Hardware Component specifications

\begin{tabular}{|c|c|}
\hline Parameters & Values \\
\hline PCV-2-564-08L (Inductor) & $560 \mu$ Henry \\
\hline
\end{tabular}

\begin{tabular}{|c|c|}
\hline SKC 3M3-45A-3 (Capacitor) & $1250 \mu F, 2350 \mu F$ \\
\hline Current sensor (LA25-P) & - \\
\hline Voltage sensor (LV25-P) & - \\
\hline F28069M microcontroller & - \\
\hline IGBT (SKM200GB1234) & - \\
\hline Load Resistance $R_{\text {load }}$ & $200 \Omega$ \\
\hline
\end{tabular}
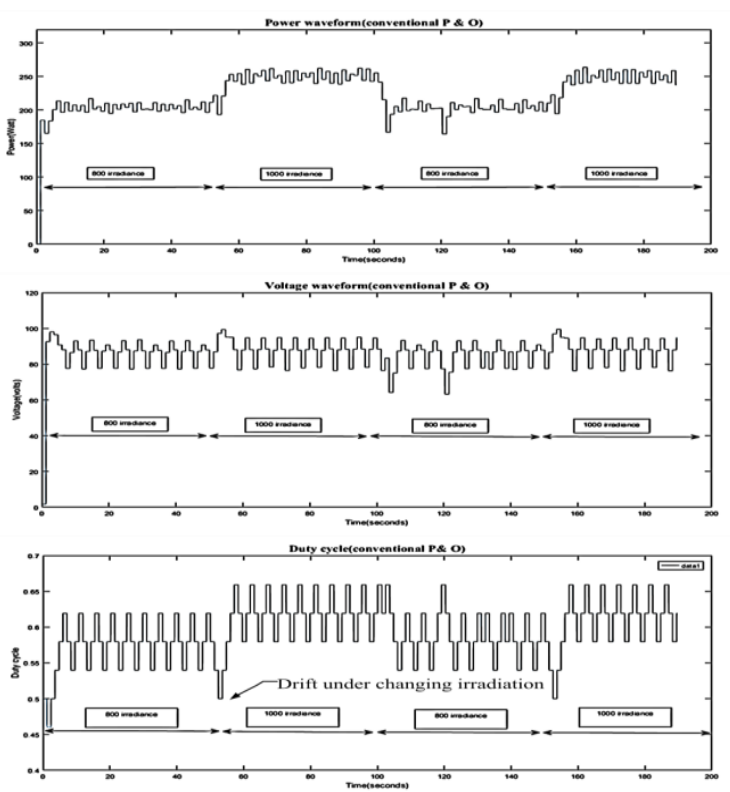

Fig. 15. Fig. 15: Current, voltage, and duty cycle waveforms for Conventional P\&O MPPT at irradiance values from $500 \mathrm{~W} / \mathrm{m} 2-800 \mathrm{~W} / \mathrm{m} 2$
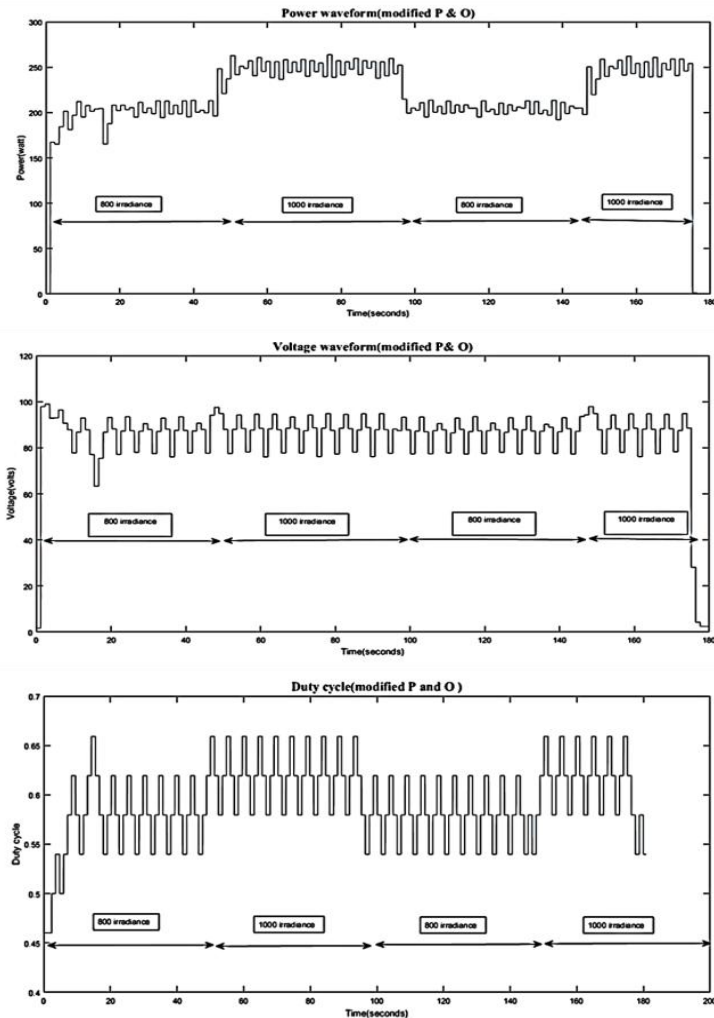

Fig. 16. Fig. 16: Current, voltage, and duty cycle waveforms for modified drift free P\&O MPPT at irradiance values from $500 \mathrm{~W} / \mathrm{m} 2-800 \mathrm{~W} / \mathrm{m} 2$ 


\section{B. Experimental Setup and Results}

Fig. 14 shows the complete Hardware setup consisting of $\mathrm{R}_{\text {load }}$, boost converter, solar emulator, and TMS320F28069M microcontroller. The data in Table- II indicates the hardware specifications. The power, voltage, and Duty ratio graphs of conventional and modified algorithms are shown in Fig. 15 \& 16 respectively. The step size was chosen to be 0.02 . Modeling of the algorithms was made such that it adjusts duty ratio under varying environmental conditions.

\section{Comparison of Experimental results of Conventional P\&O and Modified drift-free P\&O algorithm}

The modified drift-free $\mathrm{P} \& \mathrm{O}$ is tested for a varying irradiance from 800 to $1000 \mathrm{~W} / \mathrm{m}^{2}$. Both the algorithms are efficiently tracking their corresponding MPP, due to drift in $\mathrm{P} \& \mathrm{O}$ algorithm its accuracy reduces. Duty ratio comparison of both the explained algorithms is shown in Fig. 17. Whenever there in change in irradiance occurs, the $\mathrm{P} \& \mathrm{O}$ is tracking in the wrong way and adjusts itself in the right direction after some time, which may lead to power loss. At the same time, drift-free algorithm tracks the MPP accurately. Likewise, the voltage and power comparison of both the algorithms is shown in Fig. 18 \& 19 respectively.

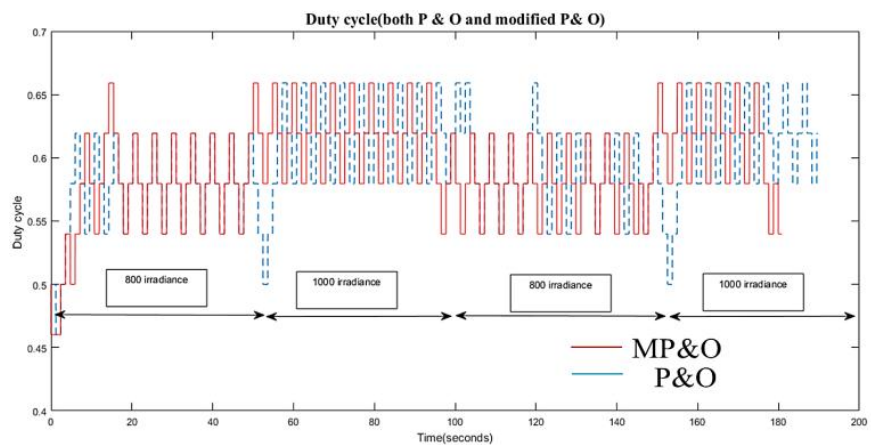

Fig. 17. Fig. 17.Duty ratio comparison

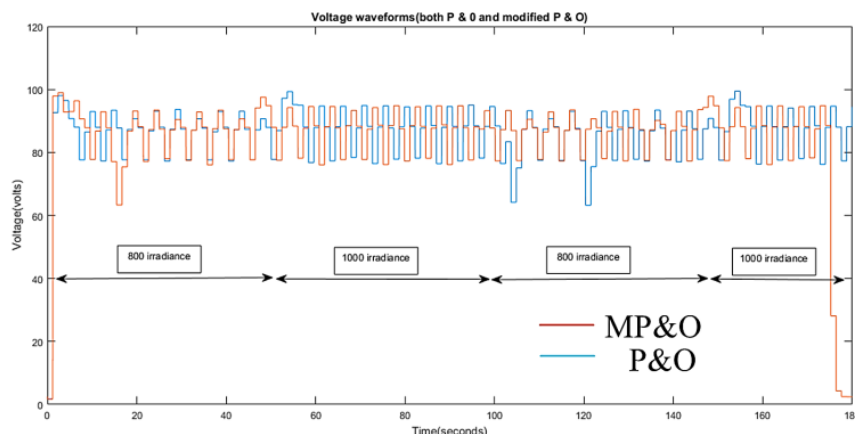

Fig. 18. Fig. 18. Voltage comparison

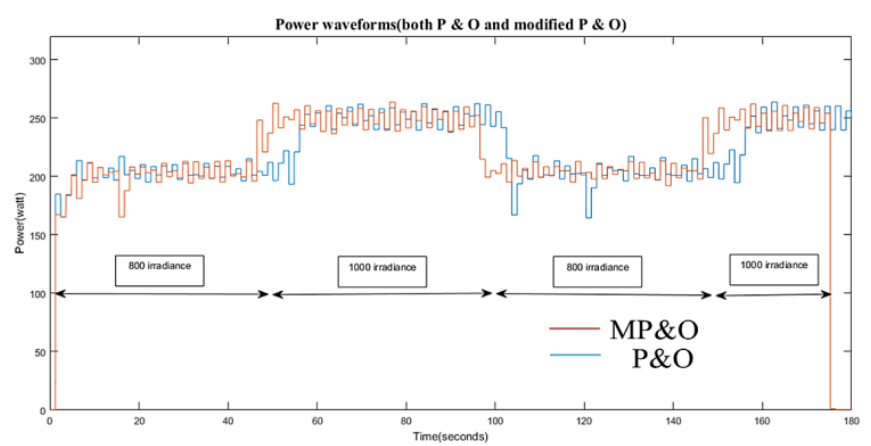

Fig. 19. Fig. 19. Power comparison

\section{CONCLUSIONS}

The perturbation based MPPT techniques for PV Systems to track MPP were presented in this paper. The perturb and observe and modified drift-free perturb and observe algorithms are modeled using MATLAB SIMULINK. An MPPT algorithm with a DC-DC boost converter is discussed, fixed iteration step size is used for these algorithms.

$\mathrm{P} \& \mathrm{O}$ Algorithm suffers from drift under varying irradiance and temperature values. Simulated MP\&O algorithm tracks the MPPT more accurately, and examined for all the irradiance values by overcoming the problem of drift. The hardware results are very much complying with the simulation results.

\section{REFERENCES}

1. L. Olatomia, S. Mekhilef, M. S. Ismail, and M. Moghavvemi, "Energy management strategies in hybrid renewable energy systems: A review," Renewable and sustainable Energy Reviews, vol. 62, pp. 821-835, 2016

2. O. Pop and S. Lungu, "Modeling of dc-dc converters," in Matlab-Modelling, Programming and Simulations. IntechOpen, 2010.

3. H. H. Mousa, A.-R. Youssef, and E. E. Mohamed, "Hybrid and adaptive sectors p\&o mppt algorithm based wind generation system," Renewable Energy, vol. 145, pp. 1412-1429, 2020.

4. M. Pathare, V. Shetty, D. Datta, R. Valunjkar, A. Sawant, and S. Pai, "Designing and implementation of maximum power point tracking (mppt) solar charge controller," in 2017 International Conference on Nascent Technologies in Engineering (ICNTE). IEEE, 2017, pp. 1-5.

5. Ali, A. I., Sayed, M. A., \& Mohamed, E. E. (2018). Modified efficient perturb and observe maximum power point tracking technique for grid-tied PV system. International Journal of Electrical Power \& Energy Systems, 99, 192-202.

6. Kota, V. R., \& Bhukya, M. N. (2017). A novel linear tangents based P\&O scheme for MPPT of a PV system. Renewable and Sustainable Energy Reviews, 71, 257-267.

7. Peng, L., Zheng, S., Chai, X., \& Li, L. (2018). A novel tangent error maximum power point tracking algorithm for photovoltaic system under fast multi-changing solar irradiances. Applied Energy, 210, 303-316.

8. Kchaou, A., Naamane, A., Koubaa, Y., \& Msirdi, N. (2017). Second order sliding mode-based MPPT control for photovoltaic applications. Solar Energy, 155, 758-769.

9. J.-H. Teng, W.-H. Huang, T.-A. Hsu, and C.-Y. Wang, "Novel and fast maximum power point tracking for photovoltaic generation," IEEE Transactions on Industrial Electronics, vol. 63, no. 8, pp. 4955-4966, 2016.

10. H. A. Sher, A. A. Rizvi, K. E. Addoweesh, and K. Al-Haddad, "A single-stage stand-alone photovoltaic energy system with high tracking efficiency," IEEE Transactions on Sustainable Energy, vol. 8, no. 2, pp. 755-762, 2016.

11. J. Ahmed and Z. Salam, "An enhanced adaptive p\&o mppt for fast and efficient tracking under varying environmental conditions," IEEE Transactions on Sustainable Energy, vol. 9, no. 3, pp. 1487-1496, 2018.

12. M. Killi and S. Samanta, "Modified perturb and observe mppt algorithm for drift avoidance in photovoltaic systems," IEEE transactions on Industrial Electronics, vol. 62, no. 9, pp. 5549-5559, 2015.

13. M. M. Rezaei and H. Asadi, "A modified perturb-and-observe-based maximum power point tracking technique for photovoltaic energy conversion systems," Journal of Control, Automation and Electrical Systems, pp. 1-10, 2019.

14. D. K. Chy, M. Khaliluzzaman, and M. M. Islam, "Comparative Experimental Analysis with and without Proposed Algorithm for MPPT using a DC-DC Converter for PV Array." Asian Journal of Engineering and Technology (ISSN: 2321-2462), Vol.3, No. 2, 2015

15. Said SAM, Hassan G, Walwil HM, Al-Aqeeli N (2018) The effect of environmental factors and dust accumulation on photovoltaic modules and dust-accumulation mitigation strategies. Renew Sustain Energy Rev $82: 743-760$ 


\section{AUTHORS PROFILE}

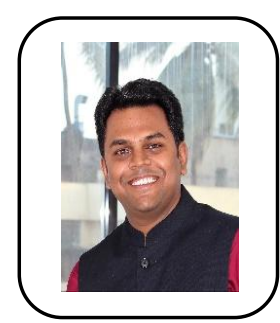

Sachin Angadi completed B. E from B.V. Bhoomaraddi College of Engineering \& Technology, Hubballi in 2011 and M.Tech. (Computers Application in Industrial Drives) from The National Institute of Engineering, Mysore in 2013. He has worked as project trainee in Control Electronics division of ISRO Satellite Centre (ISAC), Bangalore. He has over five years of teaching experience. He is presently working as Assistant Professor in the Department of Electrical \& Electronics Engineering at KLE Technological University, Hubballi. He has presented several papers in International Conferences.

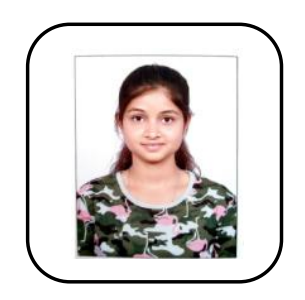

Divya Chandrashekhar Badiger is currently pursuing an undergradute in the Department of Electrical and Electronics Engineering, KLE Technological University, Hubballi, India.

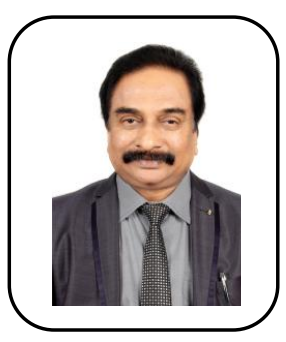

Udaykumar R. Yaragatti obtained the $\mathrm{Ph} . \mathrm{D}$. degree in energy systems engineering from the Indian Institute of Technology (IIT), Bombay, Powai, India, in 2000. In 1990, he joined, as Lecturer, the Department of Electrical and Electronics Engineering, NITK Surathkal, India, where he has served in various capacities. Currently, he is heading the Malaviya National Institute of Technology (MNIT), Jaipur, India as its Director since October 2016. He has supervised 12 Ph.D. and more than 50 M.Tech. students working in the field of power electronics. He has authored more than 80 published technical papers, and co-authored book chapters.

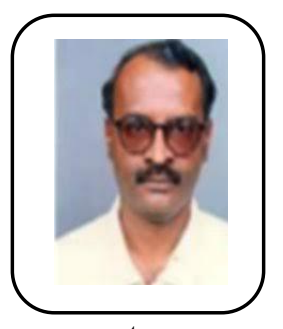

energy systems

Sri A. B. Raju is presently working as a Professor and Head, Department of Electrical and Electronics Engineering, B. V. B. College of Engineering and Technology Campus, K. L. E. Technological University, Hubballi. He obtained his M. Tech. in Machine Drives and Power Electronics from IIT, Kharagpur in 1993 and $\mathrm{PhD}$. from IIT, Bombay in the year 2005. His research interest is in the areas of power electronic, power systems, electric drive vehicles and renewable 